\title{
Research on the regulation of the spatial structure of acetylcholinesterase tetramer with high efficiency by AFM
}

This article was published in the following Dove Press journal:

International Journal of Nanomedicine

13 March 2013

Number of times this article has been viewed

\author{
Shuang Jiang' \\ Xiaobo Wang' \\ Ronggang $\mathrm{Xi}^{1}$ \\ Yingge Zhang ${ }^{2}$ \\ '210th Hospital of People Liberation \\ Army, Dalian, People's Republic of \\ China; ' Institute of Pharmacology \\ and Toxicology, Academy of Military \\ Medical Sciences, Beijing, People's \\ Republic of China
}

\begin{abstract}
Atomic force microscopy (AFM) was applied for obtaining structural information about acetylcholinesterase $(\mathrm{AChE})$ tetramer $\left(\mathrm{AChE} \mathrm{G}_{4}\right)$ before and after reaction with $\mathrm{S}$-acetylcholine iodide (S-ACh), in the presence or absence of propidium iodide (PI), an inhibitor for peripheral anionic sites (PAS). An iced-bath ultrasound was used to prepare the phospholipid membrane. Ves-fusion technique was applied for incorporating $\mathrm{AChE}_{4}$ in a lipid layer on mica. Before reaction with substrates, the single $\mathrm{AChE} \mathrm{G}_{4}$ particle was ellipsoid in shape with a clear border. It had a smooth surface with a central projection. The four subunits of a single enzyme particle were arranged tightly (no separated subunits being found, with an average size of $89 \pm 7 \mathrm{~nm}$ in length, $68 \pm 9 \mathrm{~nm}$ in width, and $6 \pm 3 \mathrm{~nm}$ in height). After reaction with S-ACh in the absence of PI, the loose arrangement of subunits of $\mathrm{AChE} \mathrm{G}_{4}$ was seen, with an average size of $104 \pm 7 \mathrm{~nm}$ in length, $91 \pm 5 \mathrm{~nm}$ in width, and $8 \pm 2 \mathrm{~nm}$ in height. Also there was free-flowing space amongst the four subunits of the $\mathrm{AChE}_{4}$. This was consistent with the results of the X-ray diffraction crystallography and molecular dynamics studies. The apparent free space was the central path of $\mathrm{AChE} \mathrm{G}_{4}$, changing from small to big, to small, to lateral door appearance, with an average size of $60 \pm 5 \mathrm{~nm}$ in length and $51 \pm 9 \mathrm{~nm}$ in width. The size of lateral door was $52 \pm 5 \mathrm{~nm}$ in width and $32 \pm 3 \mathrm{~nm}$ in depth on average. In the presence of PI, S-ACh could not cause topological structure changes of AChE $G_{4}$. AFM verified that the central path might govern the turnover of the enzyme morphologically, and the interactions between PI and S-ACh might gate the creation of a central path and the opening of ACG in monomer; and the combination of S-ACh with peripheral anionic sites is conducive to the opening of ACG while PI can inhibit this action. Resolution at the inframolecular level is favorable in providing substantial information on how the spatial structure is adapted to the high efficiency of AChE molecules.
\end{abstract}

Keywords: AChE, AFM, ACG, Ves-fusion, phospholipid membrane

\section{Introduction}

Acetylcholinesterase (AChE; E.C.3.1.1.3) is a cell-surface enzyme whose principal biological role is to terminate impulse transmission at cholinergic synapses by rapid hydrolysis of the neurotransmitter acetylcholine (ACh). The reaction is very fast, approaching the diffusion limit. ${ }^{1,2}$ However, one of the peculiarities of this single catalytic subunit of the enzyme revealed from the X-ray structure is that the active site (AS) resides in a deeply buried gorge, whose entrance is not even wide enough for the entrance of the substrate ACh. ${ }^{3}$ So it is difficult for us to understand how such a rapid enzyme at its AS is buried close to the bottom of the deep and narrow gorge. How does AChE work? How is its structure related to function?

The active center gorge (ACG) of AChE involves at least two substrate binding sites: the AS and the peripheral anionic sites (PAS). ${ }^{4-6}$ The PAS on AChE is located at the
Correspondence: Yingge Zhang Institute of Pharmacology and Toxicology, Academy of Military Medical Sciences, 2255 Room, North building, 27 Taiping Road, Haidian District, Beijing 100850, People's Republic of China Tel +8601066930654 Email zhangyg58@I26.com 
ACG entry near the enzyme surface. Binding of the ligands at the PAS affects catalytic activity. Molecular dynamic simulations have shown that the width of the entrance is not fixed, but rather fluctuates. ${ }^{7,8}$ Recent literature suggests that PAS and AS are both the binding and discharging sites of substrates. ${ }^{9}$ Normal mode analysis suggested that AChE $\mathrm{G}_{4}$ could exist in several conformations with subunits fluctuating relative to one another. ${ }^{10,11}$ The intersubunit fluctuation is correlated with the occlusion of PAS. Such motions of the subunits "gate" ligand-protein association are known. Understanding of the accommodation of PAS on AChE $\mathrm{G}_{4}$ to its high efficiency of hydrolyzing substrates is therefore essential for understanding its remarkable catalytic efficacy and rational drug design. These results serve as the inspiration to determine whether there is a way to "see" how the enzyme works and how the subunits change in the presence of $\mathrm{ACh}$, even if there are only some "photos" of reacting enzymes.

For the past two decades, AFM has been a forceful tool for observing the structures of cells and biomacromolecules. The image analysis of AFM on the biological system is of higher resolution than that of optical microscopes, and its sample preparation is more appropriate to its physiological condition than for electron microscopes. It also offers more direct viewing than spectroscopy, which usually provides indirect reasoning about structural information from a bulk of light spectrum signals. Compared with crystallography, image analysis of AFM does not demand a crystal sample, which allows us to study native biological specimens. We hypothesize that using powerful AFM will enable us to observe the changes in the morphology of enzymes while hydrolyzing ACh.

AChE is a membrane protein anchored to the cell membranes, and it is usually separated only with difficulty, which complicates their study. For the past few years, our team reconstituted purified AChE into a phospholipid membrane, simplifying our study and removing any disturbances, thereby facilitating our study on the structure and function of AChE.

In this work, AFM was applied to obtain structural information about $\mathrm{AChE} \mathrm{G}_{4}$ before and after reaction with S-acetylcholine iodide (S-ACh), in the presence or absence of PI (an inhibitor for PAS). According to the structural changes of $\mathrm{AChE}$, we proposed the possible regulation mechanism behind its high efficiency.

\section{Materials and methods Reagents}

$\mathrm{AChE}_{4}$ from an electric eel was purchased from SigmaAldrich (type V-S, C2888, 1310 units/mg of protein, with a molecular weight of $280 \mathrm{KDa}$; Sigma-Aldrich, St Louis, MO, USA). S-ACh and propidium iodide (PI) were also purchased from Sigma-Aldrich.

\section{Reconstitution of phospholipid membranes on mica by Ves-fusion technique}

Lecithin (10 mg) was put on the rim of a round bottom flask and dissolved thoroughly in $10 \mathrm{~mL}$ of $\mathrm{MeOH} / \mathrm{CHCl}_{3}$ ( $4: 1$ ratio). The organic solvents were removed by rotary vacuum evaporator (EYELA WORLD, Tokyo Rikakikai Co, Tokyo, Japan), forming a thin layer of phospholipid film on the wall of the flask. The thin film was redissolved and then resuspended in a $10 \mathrm{~mL}$ Tris- $\mathrm{NaCl}(0.1 \mathrm{M}, \mathrm{pH} 7.4)$ solution. ${ }^{12}$ The mixed lecithin suspension was placed in intermittent iced-bath ultrasound fields (frequency, $80 \mathrm{~Hz}$ ) for more than 3 hours to form a phospholipid liposome solution. Optimal results were obtained when the ultrasound was terminated just before clarification. A total of $2 \mathrm{~mL}$ of a prepared liposome solution were injected slowly into the container filled with double distilled water, with a piece of mica floating on its surface. After being incubated for 4 hours at room temperature $\left(24^{\circ} \mathrm{C}\right)$, phospholipid membranes were formed spontaneously at the mica-water interface. This proceeded in several distinct steps: adsorption, collapse, and rupture. ${ }^{13-17}$

\section{The reactions between $\mathrm{AChE} \mathrm{G}_{4}$ and its substrate in the presence or absence of PI}

In all, $50 \mu \mathrm{L}, 3 \mathrm{mM}$ of S-ACh (phosphate buffer, $0.1 \mathrm{M}$, $\mathrm{pH}=8.0$ ) was added into the AChE-lecithin suspension and incubated in a water bath at $37^{\circ} \mathrm{C}$ for 20 minutes before the finish of the reconstitution; the ultimate reaction concentrations of S-ACh and AChE were $7 \mu \mathrm{M}$ and $10 \mu \mathrm{g} / \mathrm{mL}$, respectively. In the PAS inhibitor group, the same concentration of S-ACh was added to the AChE-PI solution after it had been reacted for 30 minutes; subsequent incubation and Ves-fusion is the same, as above.

\section{Atomic force microscopy}

The mica with phospholipids, and the mica with reconstituted AChE proteins, were rinsed gently with flowing double distilled water five times. The mica was then cut into pieces of $1 \mathrm{~cm} \times 1 \mathrm{~cm}$, and fixed on the base of the AFM by double-faced glue. Imaging was performed in tapping mode and contact mode using a 9500J3 AFM (Shimadzu Corporation, Kyoto, Japan) and the scan size was $30 \mu \mathrm{m}$. V-shaped oxide-sharpened 
$\mathrm{Si}_{3} \mathrm{~N}_{4}$ cantilevers with spring constants of $0.57 \mathrm{~N} / \mathrm{m}$ (Olympus Corporation, Tokyo, Japan) were used for scanning in the air. The start parameters included: scan size, $30 \mu \mathrm{m}$; frequency, $5 \mathrm{~Hz}$; proportional gain, 0.0001; integral gain, 20. Images $(256 \times 256$ pixels $)$ were captured with scan sizes between $1 \mu \mathrm{m}^{2}$ and $30 \mu \mathrm{m}^{2}$ at a scan rate of up to $5 \mathrm{~Hz}$. The ambient temperature was kept at $25^{\circ} \mathrm{C}$ with humidity less than $30 \%$. Images were processed using AFM offline handling software.

\section{Results}

\section{AFM imaging of the reconstituted phospholipid membranes in contact mode}

Figure 1 is the phospholipid membrane reconstituted on the freshly cleaved mica. Figure 1A is the large-scale view of the phospholipid membrane. Figure 1B is the higher-magnification view showing a region of flattened membrane with some pore spaces. The light region is the phospholipid membrane, and the dark region is the exposed mica surface. The fusion of the membrane is perfect, with no apparent defects. Lines $\mathrm{AB}, \mathrm{CD}$, and $\mathrm{EF}$ are examples of AFM topographic line profiles of the membrane, and the measurement of the height difference between the rim of membrane and exposed mica shows that the height of the phospholipid membrane is $2.3 \mathrm{~nm}$ $(n=30)$, which is the thickness of a single lipid layer. ${ }^{18}$

\section{AFM imaging of the reconstituted AChE $\mathrm{G}_{4}$ in the phospholipid membrane in tapping mode}

Figure 2 illustrates the AFM images of $\mathrm{AChE} \mathrm{G}_{4}$ reconstituted into phospholipid membranes on mica in tapping mode. Images were collected by height mode and by phase mode simultaneously. $\mathrm{AChE}_{4}$ can be seen clearly having been reconstituted into phospholipids in Figure 2B, as indicated by white arrows. From Figure 2B we can see some minute information, including that the rim of the protein was reconstituted into membranes as displayed, suggesting that there were some interactions between proteins and lipids; there were borders between membranes, indicated by the white rectangle and circle, neither of which were seen from the height map (Figure 2A).

\section{AFM imaging of $A C h E G_{4}$ incorporated in a mica-supported artificial lipid layer in contact mode}

Figure 3 offers the comparisons of the AFM images of $A C h E G_{4}$ incorporated in a lipid layer on mica before reaction with substrates (Figure $3 \mathrm{~A}$ ), and after reaction with $\mathrm{S}-\mathrm{ACh}$, in the absence (Figure 3B-E) or presence of PI (Figure 3F), an inhibitor for PAS. The same zone or the same protein was repetitively scanned, and the image was not changed. This indicates that membrane protein was apparently not damaged by the scanning of the AFM tip. AChE $\mathrm{G}_{4}$ particles were uniformly distributed in the phospholipid membrane with a spherical or ellipsoid shape (Figure 3A). Before reaction with substrates, the single $\mathrm{AChE} \mathrm{G}_{4}$ particle was ellipsoid in shape with a clear border, it had a smooth surface with a central projection, and the four subunits of single enzyme particles were arranged tightly (no separated subunits were found), with the average size being of $89 \pm 7 \mathrm{~nm}$ in length, $68 \pm 9 \mathrm{~nm}$ in width and $6 \pm 3 \mathrm{~nm}$ in height.

The volume of $\mathrm{AChE} \mathrm{G}_{4}$ after its reaction with $\mathrm{S}-\mathrm{ACh}$ in the absence of PI (Figure 3B-D) is larger than that seen in Figure $3 \mathrm{~A}, \mathrm{~F}$, and a gorge appears in some reacted proteins (Figure 3B-D). The loose arrangement of subunits of $\mathrm{G}_{4}$ $\mathrm{AChE}$ is the most obvious effect following ACh in the absence of PI, with the average size being $104 \pm 7 \mathrm{~nm}$ long, $91 \pm$ $5 \mathrm{~nm}$ wide, and $8 \pm 2 \mathrm{~nm}$ high, and there is an apparent free space in the center of $\mathrm{AChE} \mathrm{G}_{4}$, with the average size being $60 \pm 5 \mathrm{~nm}$ long and $51 \pm 9 \mathrm{~nm}$ wide. Figure $3 \mathrm{~B}-\mathrm{D}$ represents different statuses of $\mathrm{AChE} \mathrm{G}_{4}$ when reacted with S-ACh in the absence of PI. The structure of $\mathrm{AChE} \mathrm{G}_{4}$ after its reaction with $\mathrm{S}-\mathrm{ACh}$ is looser than seen in Figure 3A, and the enzyme is composed of subunits; there are linkages among the subunits (Figure 3C). A loose, pseudo-square planar tetramer of AChE after its reaction with S-ACh appears in (Figure 3C), and one protein particle is composed of two pairs of subunits; there are linkages in the lateral groups of one subunit, consisting of one pair of subunits with that of another pair (Figure 3C). With certain conditions, we found units composed of tightened $\mathrm{AChE} \mathrm{G}_{4}$ (Figure 4D), and some $\mathrm{AChE} \mathrm{G}_{4}$ emerged in the structure of the "lateral door" (Figure 3E); the average size of the lateral door was $52 \pm 5 \mathrm{~nm}$ in width and $32 \pm 3 \mathrm{~nm}$ in depth. Compared with Figure 3B-E, in the presence of PI (PAS inhibitor), ACh did not cause topological structure changes of $\mathrm{AChE} \mathrm{G}_{4}$ (Figure 3F).

\section{AFM high-resolution three-dimensional imaging of $\mathrm{AChE} \mathrm{G}_{4}$ incorporated in a mica-supported artificial lipid layer in contact mode}

Figure 4 is comprised of the comparison of high-resolution AFM images of $\mathrm{AChE} \mathrm{G}_{4}$ incorporated in a lipid layer on mica before 


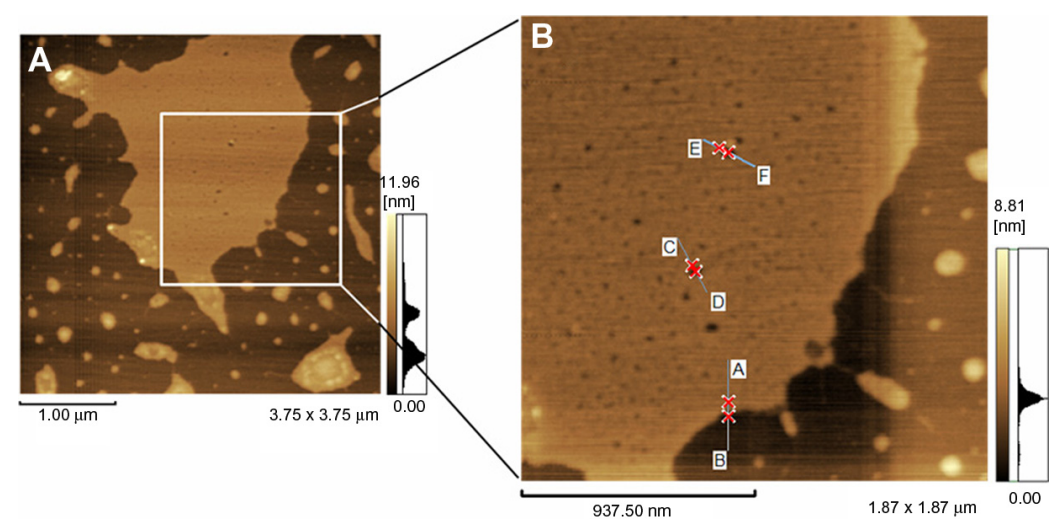

Line A-B 3.23

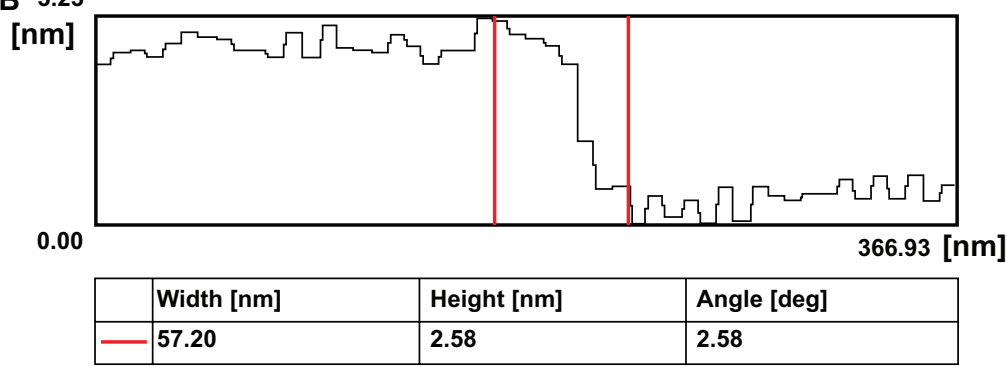

Line C-D 2.56

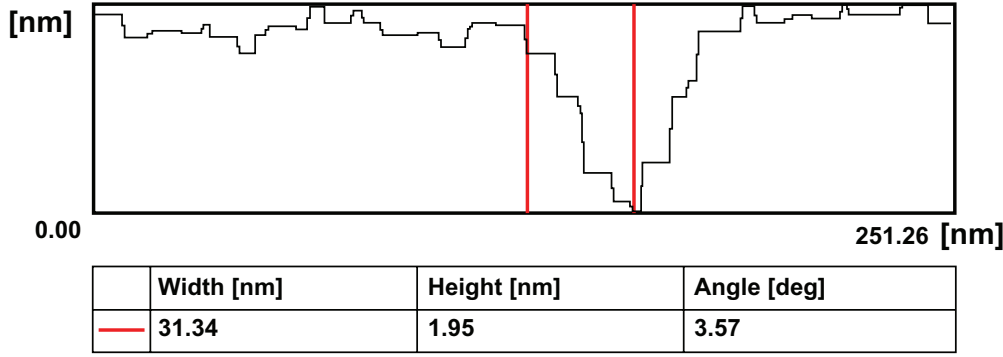

Line E-F 3.01

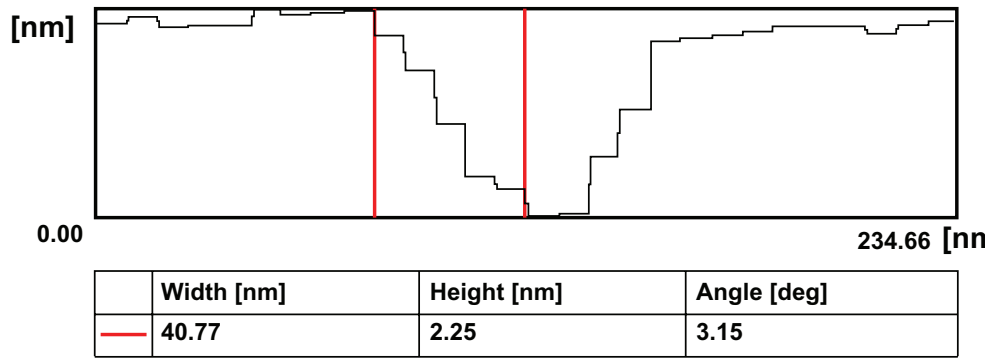

Figure I AFM images presented in contact mode of phospholipid membrane reconstituted on mica. (A) Large-scale view of a phospholipid membrane. (B) Higher magnification view showing a region of flattened membrane with some pore spaces.

Notes: Light region is phospholipid membrane, and dark region is surface of exposed mica. The fusion of the membrane is perfect; not seeing apparent defects. Lines $A B$, $\mathrm{CD}$, and $\mathrm{EF}$ are examples of AFM topographic line profiles of the membrane. The measurements of the height difference between the rim of the membrane show that the height of the phospholipid membrane is on average $2.26 \mathrm{~nm}(\mathrm{n}=30)$, which is the thickness of a lipid's single layer.

Abbreviations: AFM, atomic force microscopy; deg, degree; $\mu \mathrm{m}$, micrometers; $\mathrm{nm}$, nanometers.

(Figure 4A, B) and after reaction with $\mathrm{S}-\mathrm{ACh}$, in the absence (Figure 4C, D, E, F) or presence of PI (Figure 4G, H), an inhibitor for PAS. Figure $4 A, C, E$ and $G$ are the magnifications of the proteins circled in the white rectangle in Figure 3A, D, E and F, respectively; Figure 4B, D, F and $\mathrm{H}$ are the high-resolution three-dimensional images of the proteins circled. A single $\mathrm{G}_{4} \mathrm{AChE}$ particle before it reacted with ACh is ellipsoid and smooth, with a center projection and clear border (Figure 4A 

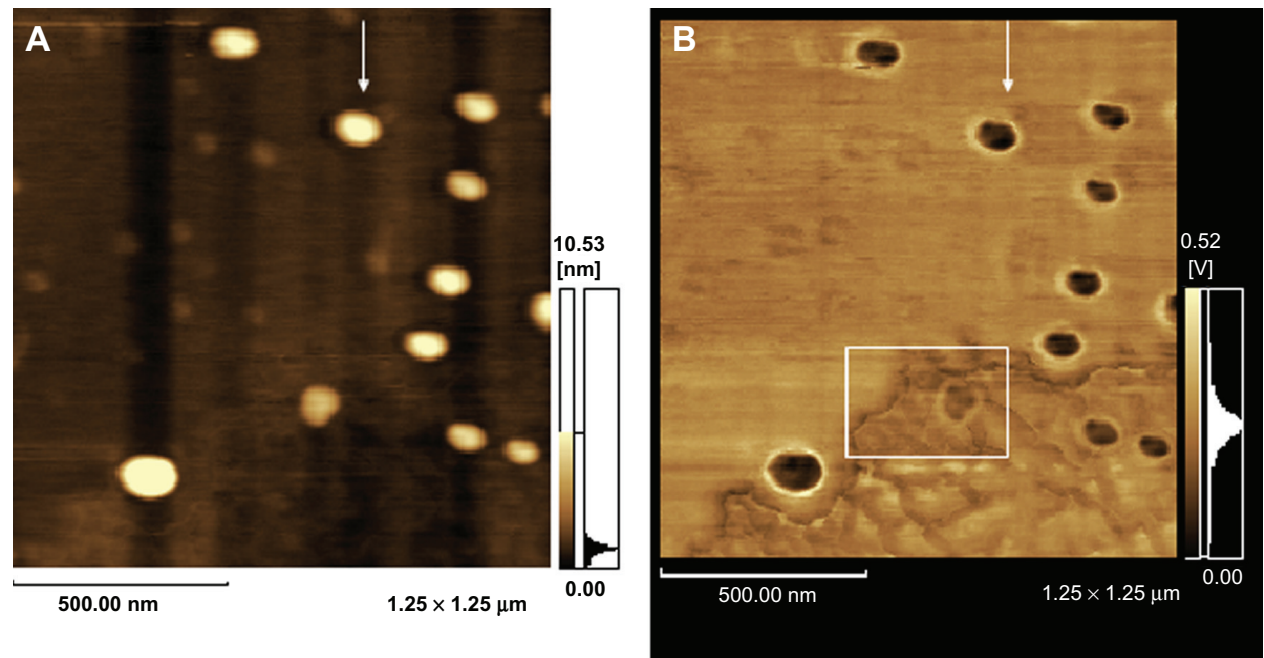

Figure 2 AFM images presented in the tapping mode of $A C h E G_{4}$ incorporated in a lipid layer on mica. Images are collected by (A) height mode and (B) phase mode, simultaneously. The same $\mathrm{AChE} \mathrm{G}_{4}$ particle incorporated in a lipid layer is indicated by white arrows, and can be seen clearly in (A and $\left.\mathbf{B}\right)$. From (B), we can see some minute information, including the rim of protein reconstituted into membranes, which is highlighted, suggesting that there are some interactions between proteins and lipids. There are borders between the membranes, indicated by the white rectangle and circle, which are both not seen from the height map (A).

Note: All image sizes are $1.87 \mu \mathrm{m} \times 1.87 \mu \mathrm{m}$.

Abbreviations: AFM, atomic force microscopy; $\mathrm{AChE} \mathrm{G}_{4}$, acetylcholinesterase tetramer; $\mu \mathrm{m}$, micrometers; nm, nanometers; $v$, volts.
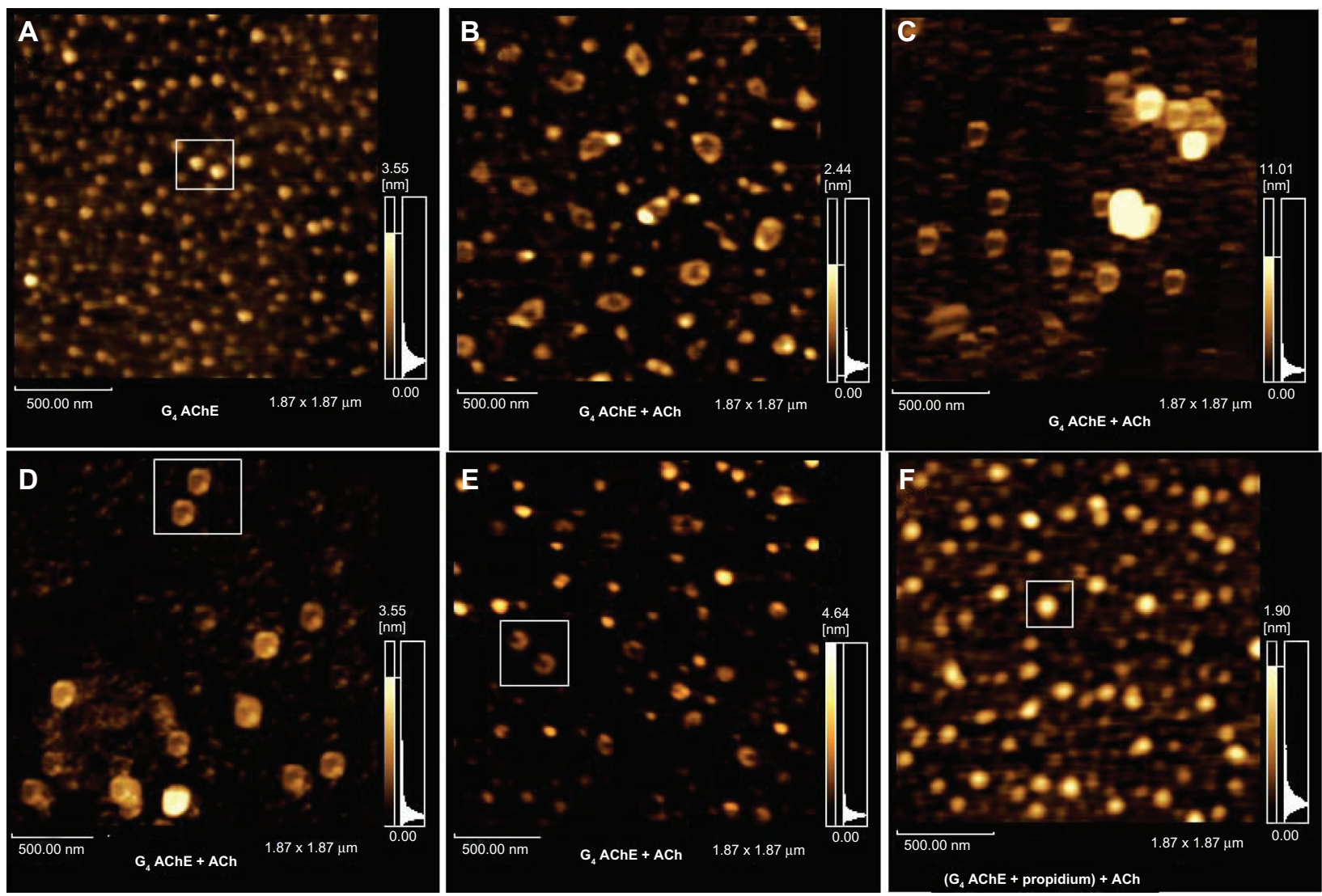

Figure 3 Comparisons of AFM images of $A C h E G_{4}$ incorporated in a lipid layer on mica (A) before reaction with substrates, and (B-E) after reaction with S-ACh in the absence or $(\mathbf{F})$ presence of $\mathrm{Pl}$, an inhibitor for peripheral anionic sites. The loose arrangement of the subunits of $A C h E G_{4}$ is the most obvious effect followed by $\mathrm{S}$ - $\mathrm{ACh}(\mathbf{B}-\mathbf{E})$, and the volume of $\mathrm{AChE} \mathrm{G}_{4}$ after reaction with $\mathrm{S}-\mathrm{ACh}$ is larger than $(\mathbf{A})$, and there is an apparent free space in the center of $A C h E G_{4}$, changing from $(\mathbf{B})$ small to $(\mathbf{C})$ big, to (D) small, to (E) a lateral door appearance. (F) In the presence of a PAS inhibitor, S-ACh could not cause topological structure changes of AChE G.

Note: All image sizes are $1.87 \mu \mathrm{m} \times 1.87 \mu \mathrm{m}$.

Abbreviations: AFM, atomic force microscopy; $\mathrm{AChE} \mathrm{G}_{4}$, acetylcholinesterase tetramer; ACh, acetylcholine; $\mu \mathrm{m}$, micrometers; nm, nanometers; S-ACh, S-acetylcholine iodide; PI, propidium iodide; PAS, peripheral anionic sites. 

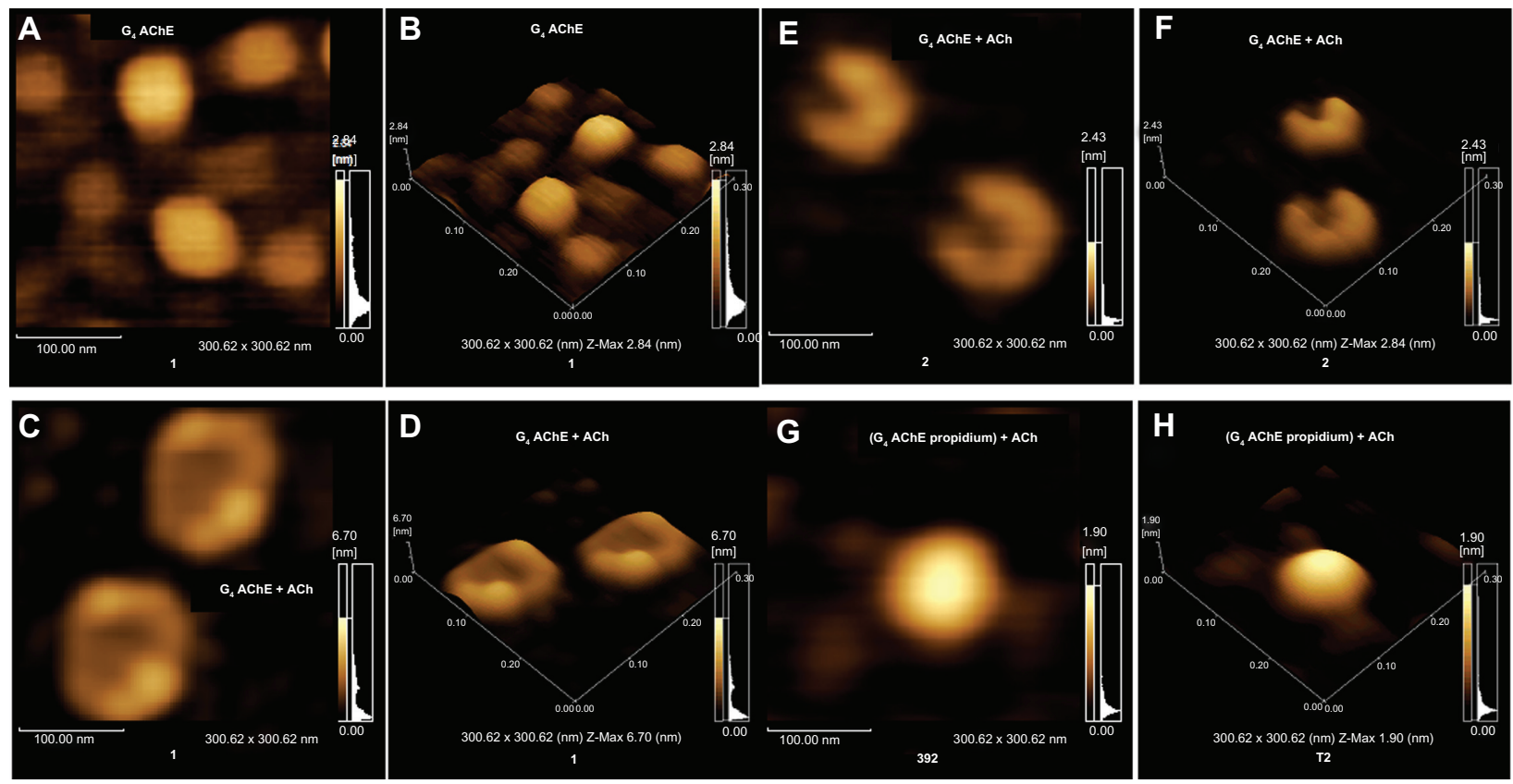

Figure 4 Comparisons of high-resolution AFM images of AChE G incorporated in a lipid layer on mica $(\mathbf{A})$ before and $(\mathbf{C}$ and $\mathbf{E})$ after reaction with S-ACh in the absence or (G) presence of $\mathrm{Pl}$, an inhibitor for peripheral anionic sites. (A, C, E and $\mathbf{G}$ ) are the magnification of the proteins circled in (Figure $\mathbf{3} \mathbf{A}, \mathbf{D}$, $\mathbf{E}$ and $\mathbf{F}$ ), respectively, and (B, D, F, and $\mathbf{H}$ ) are their corresponding high-resolution three-dimensional images. (A and $\mathbf{B})$ A single AChE G $_{4}$ particle before reaction with S-ACh is ellipsoid and smooth with a center projection and clear border. ( $\mathbf{G}$ and $\mathbf{H}$ ) In the presence of PI, the topological structure of $A C h E G_{4}$ has not changed.

Note: All image sizes are $300.62 \mathrm{~nm} \times 300.62 \mathrm{~nm}$.

Abbreviations: AFM, atomic force microscopy; $A \mathrm{AChE} \mathrm{G}_{4}$, acetylcholinesterase tetramer; nm, nanometers; S-ACh, S-acetylthiocholine iodide; PI, propidium iodide.

and B). There is a free space in the middle of $\mathrm{AChE} \mathrm{G}_{4}$ after its reaction with $\mathrm{ACh}$, namely the central path of $\mathrm{AChE} \mathrm{G}_{4}$ (Figure 4C and D). There is a lateral door structure in Figure 4E and F. In the presence of PI (PAS inhibitor), the topological structure of $\mathrm{G}_{4} \mathrm{AChE}$ has not changed (Figure $4 \mathrm{G}$ and $\mathrm{H}$ ).

\section{Discussion}

To investigate why AChE has a surprisingly high efficiency in hydrolyzing substrates has always been an aim in studies in the life sciences. Colletier et $\mathrm{al}^{9}$ have presented the crystal structures of Torpedo californica AChE complexed with the substrate, acetylthiocholine, the product of which was thiocholine and a nonhydrolysable substrate analogue. These structures provide a series of static snapshots of the substrate en route to the AS, and they identify, for the first time, the binding of the substrate and product at both the peripheral and AS. Our study observed the obvious effect of ACh on the submolecular structure of AChE $G_{4}$ incorporated in a mica-supported artificial lipid layer with AFM; the characteristic of the effect is a loose arrangement of the subunits of $\mathrm{AChE} \mathrm{G}_{4}$ (the protein is in physiological condition and not in a crystal state), and there is an apparent free space that appears in the center of $\mathrm{AChE} \mathrm{G}_{4}$. The apparent free space was the central path of $\mathrm{AChE} \mathrm{G}_{4}$, changing from small to big, to small, to a lateral door appearance, which is adapted to its high efficiency of hydrolyzing substrates; in the presence of the PAS inhibitor, ACh could not cause the topological structure changes of $\mathrm{AChE} \mathrm{G}_{4}$, which has not been reported by others.

According to the changes of the submolecular structure of $\mathrm{AChE} \mathrm{G}_{4}$ after its reaction with $7 \mu \mathrm{M} \mathrm{S}-\mathrm{ACh}$, we raised the possible mechanism of high-efficiency $\mathrm{AChE}$ in hydrolyzing substrates: before their reaction with substrates, the four subunits of a single enzyme particle were arranged tightly, which may facilitate the protection of the active center of $\mathrm{AChE} \mathrm{G}_{4}$ from being occupied by other molecules. Subunits of $\mathrm{AChE} \mathrm{G}_{4}$ are arranged more loosely on the attack of $\mathrm{ACh}$, which makes the solvent accessible to the deepest of the four subunits, in which the active centers exist. The loose arrangement of the four subunits also makes the PAS more exposed, facilitating the access of the substrates, so the loose arrangement of subunits might govern the turnover of the enzyme. The reaction between $\mathrm{AChE} \mathrm{G}_{4}$ and $\mathrm{ACh}$ might be via the possible key procedures as follows: (1) there are only two PASs of tightly normal $\mathrm{AChE} \mathrm{G}_{4}$ that have been exposed, and the cationic substrate AChs are attracted by the strong electrostatic field of $\mathrm{AChE}$ to combine with the exposed PASs at the presence of ACh; (2) ACG of the monomer of $\mathrm{AChE} \mathrm{G}_{4}$ is open, and $\mathrm{AChs}$ enter the bottom of the ACG; (3) substrates are hydrolyzed; (4) the 
repulsion among the subunits of $\mathrm{AChE}_{4}$ are increased greatly, forming a central path among them, and the four PASs are even more exposed by the allosterism of subunits; (5) the products of choline and acetic acid combined with the AS of the monomer of $\mathrm{AChE}_{4}$ arrive at the central path via the "back door" of the monomer; (6) the "lateral door" of the enzyme is open, and the enzyme tightens it further; (7) the products leave enzyme; and (8) the enzyme recovers to the normal state. The changes of the submolecular structure of $\mathrm{AChE}_{4}$ are adapted to the high efficiency of AChE hydrolyzing the substrates.

The combination of the ACh with PAS might gate the openness of ACG and give rise to the openness status of the ACG, providing a path for following abundant ACh molecules to get to the catalytic site of the active centers of the monomer. The most straightforward interpretation of these results is that these changes of submolecular structure result in the structure's remarkable catalytic efficacy. In the presence of propidium, which is a noncompetitive inhibitor for binding to the peripheral site, ACh could not cause topological structure changes of $\mathrm{AChE} \mathrm{G}_{4}$. On one hand, it is related to the PAS of AChE. AChE is of high catalytic efficiency; ligand binding and X-ray crystallography suggested that the role of PAS in hydrolysis, and the ligand's specific combination with the catalytic site of ACG is first though the PAS, and then it arrives there. On the other hand, this is related to stereospecific blockade. PAS inhibitors affect the binding of $\mathrm{ACh}$, which suggests that the site at which they bind is equivalent to, or overlaps with, the PAS for ACh. PAS inhibitors have been shown to inhibit catalysis through a combination of steric blockade of ligands entering and leaving the gorge, and allosteric alteration conformation and efficiency of the catalytic triad. AFM verified that the interactions between PAS and ACh might gate the openness status of ACG morphologically; the combination of ACh with PAS facilitates the openness of ACG. The PAS inhibitor can inhibit this action.

The flat surface and regular atomic structure of basal pieces are necessary for the lipid molecular self-assembly to occur on it. Mica has good chemical stability and atomic level flatness; therefore, it is obviously an ideal membrane-forming substrate. The surface of mica is hydrophilic, which makes it likely to combine with the polar groups of the lipid molecule. The adsorption effect depends on the size of the static electricity bonding force and molecular distribution density between the substrate surface and adsorbed molecules. The surface of mica is negatively charged, but the polar head groups of the lipid molecule are positively charged. The ion exchange between $\mathrm{K}^{+}$of the mica surface and the ions of the polar head groups of lipids increases the electrostatic repulsion, preventing the long tail of lipids spreading on the mica angularly, availing the regular self-assembly of lipid membranes.

AFM is still a new technique now, and its application in biomedicine is not yet universal. Many phenomena are hard to reconcile completely with these study results. For example, the size found for $\mathrm{AChE}_{4}$ is much larger than the results of the X-ray crystallography and electron microscopy show. First, the preparation method of the sample is different, such that the sample proteins in the X-ray crystallography are crystallized, while our sample is native. The water content of the two samples might be different. The water content of the crystallized sample is fixed. Although our AFM images are acquired in the atmosphere of air, the water content of the sample might still be larger than the crystallized sample. A layered water membrane can be formed on the surface of even dried samples after the absorption of water in the air, which is a phenomenon that is hard to overcome in some study samples. Furthermore, physiologically, our sample might be closer to the native environment of the enzyme due to its larger water content. Second, the protein's larger bulk may be due to the AFM probe's pressure on the enzyme, or due to tip-broadening in the AFM imaging to some degree. With all of these differences, many AFM results are in agreement with those of other techniques, such as the four subunits of the functional $\mathrm{AChE}$ polymer. An obvious advantage of AFM is the easy preparation of the samples, which makes it capable of studying the structural relations of biomacromolecules. In this present study, the AFM was applied to observe the regulation of the spatial structure of AChE G4 with high efficiency has not been reported by others; it is complementary to previously published studies on AChE.

\section{Conclusion}

AFM can observe the changes in the submolecular structure of enzymes. The changes of the submolecular structure of $\mathrm{AChE}_{4}$ are adapted to the high efficiency of AChEhydrolyzing substrates. AFM verified that the central path might govern the turnover of the enzyme morphologically, and the interactions between PAS and ACh might gate the creation of the central path and the opening of ACG in the monomer; and the combination of ACh with PAS is conducive to the opening of ACG while a PAS inhibitor can inhibit this action. Resolution at the inframolecular level is favorable for providing substantial information on the relative orientations of the subunits within the polymer of the enzyme under the effect of substrates or a substrate inhibitor. 


\section{Acknowledgments}

This work was supported by the Chinese Major Projects for Nanoresearch No 2010CB933904, and the Chinese Major Projects for New Drug Creation No 2001ZX09102-001-15.

\section{Disclosure}

The authors report no conflicts of interest in this work.

\section{References}

1. Rosenberry TL. Acetylcholinesterase. Adv Enzymol Relat Areas Mol Biol. 1975;43:103-218.

2. Silman I, Sussman JL. Acetylcholinesterase: 'classical' and 'nonclassical' functions and pharmacology. Curr Opin Pharmacol. 2005;5(3): 293-302.

3. Sussman JL, Harel M, Frolow F, et al. Atomic structure of acetylcholinesterase from Torpedo californica: a prototypic acetylcholine-binding protein. Science. 1991;253(5022):872-879.

4. Mallender WD, Szegletes T, Rosenberry TL. Acetylthiocholine binds to asp74 at the peripheral site of human acetylcholinesterase as the first step in the catalytic pathway. Biochemistry. 2000;39(26):7753-7763.

5. Johnson JL, Cusack B, Hughes TF, et al. Inhibitors tethered near the acetylcholinesterase active site serve as molecular rulers of the peripheral and acylation sites. J Biol Chem. 2003;278(40):38948-38955.

6. Rosenberry TL, Johnson JL, Cusack B, Thomas JL, Emani S, Venkatasubban KS. Interactions between the peripheral site and the acylation site in acetylcholinesterase. Chem Biol Interact. 2005;157-158: 181-189.

7. Wlodek ST, Clark TW, Scott LR, McCammon JA. Molecular dynamics of acetylcholinesterase dimer complexed with tacrine. J Am Chem Soc. 1997;119(40):9513-9522.

8. Tai K, Shen T, Börjesson U, Philippopoulos M, McCammon JA. Analysis of a 10-ns molecular dynamics simulation of mouse acetylcholinesterase. Biophys J. 2001;81(2):715-724.
9. Colletier JP, Fournier D, Greenblatt HM, et al. Structural insights into substrate traffic and inhibition in acetylcholinesterase. EMBO J. 2006;25(12):2746-2756.

10. Fernandez HL, Moreno RD, Inestrosa NC. Tetrameric $\left(G_{4}\right)$ acetylcholinesterase: structure, localization, and physiological regulation. J Neurochem. 1996;66(4):1335-1346.

11. Gorfe AA, Chang CA, Ivanov I, McCammon JA. Dynamics of the acetylcholinesterase tetramer. Biophys J. 2008;94(4):1144-1154.

12. Merino S, Domènech O, Díez-Pérez I, Sanz F, Montero MT, Hernández-Borrell J. Surface thermodynamic properties of monolayers versus reconstitution of a membrane protein in solid-supported bilayers. Colloids Surf B Biointerfaces. 2005;44(2-3):93-98.

13. You HX, Qi X, Yu L. Direct AFM observation of saposin C-induced membrane domains in lipid bilayers: from simple to complex lipid mixtures. Chem Phys Lipids. 2004;132(1):15-22.

14. Reviakine I, Brisson A. Formation of supported phospholipid bilayers from unilamellar vesicles investigated by atomic force microscopy. Langmuir. 2000;16(4):1806-1815.

15. Richter RP, Brisson A. Characterization of lipid bilayers and protein assemblies supported on rough surfaces by atomic force microscopy. Langmuir. 2003;19(5):1632-1640.

16. Richter R, Mukhopadhyay A, Brisson A. Pathways of lipid vesicle deposition on solid surfaces: a combined QCM-D and AFM study. Biophys J. 2003;85(5):3035-3047.

17. Roes S, Mumm F, Seydel U, Gutsmann T. Localization of the lipopolysaccharide-binding protein in phospholipid membranes by atomic force microscopy. J Biol Chem. 2006;281(5):2757-2763.

18. Helm CA, Möhwald H, Kjaer K, Als-Nielsen J. Phospholipid monolayers between fluid and solid states. Biophys J. 1987;52(3): 381-390.
International Journal of Nanomedicine

\section{Publish your work in this journal}

The International Journal of Nanomedicine is an international, peerreviewed journal focusing on the application of nanotechnology in diagnostics, therapeutics, and drug delivery systems throughout the biomedical field. This journal is indexed on PubMed Central, MedLine, CAS, SciSearch ${ }^{\circledR}$, Current Contents ${ }^{\circledR} /$ Clinical Medicine,

\section{Dovepress}

Journal Citation Reports/Science Edition, EMBase, Scopus and the Elsevier Bibliographic databases. The manuscript management system is completely online and includes a very quick and fair peer-review system, which is all easy to use. Visit http://www.dovepress.com/ testimonials.php to read real quotes from published authors. 